\title{
Review Article \\ Interactive Whiteboards in Mathematics Teaching: A Literature Review
}

\author{
Mauro De Vita, Lieven Verschaffel, and Jan Elen \\ Centre for Instructional Psychology and Technology, K.U. Leuven, Dekenstraat 2, 3000 Leuven, Belgium \\ Correspondence should be addressed to Mauro De Vita; mauro.devita@student.kuleuven.be
}

Received 17 December 2013; Revised 4 April 2014; Accepted 14 April 2014; Published 22 May 2014

Academic Editor: Stefan Fries

Copyright (C) 2014 Mauro De Vita et al. This is an open access article distributed under the Creative Commons Attribution License, which permits unrestricted use, distribution, and reproduction in any medium, provided the original work is properly cited.

\begin{abstract}
An interactive whiteboard (IWB) is a relatively new tool that provides interesting affordances in the classroom environment, such as multiple visualization and multimedia presentation and ability for movement and animation. These affordances make IWBs an innovative tool with high potential for mathematics instructional environments. IWBs can be used to focus on the development of specific mathematical concepts and to improve mathematical knowledge and understanding. The aim of this paper is to review the existing literature upon the use of interactive whiteboards (IWBs) in mathematics classrooms. The reviewed studies offer a wide view of IWBs' affordances, of the more interesting didactic practices, and of the difficulties of embedding this new technology in the classroom. The capabilities of IWBs to enhance the quality of interaction, and, consequently, to improve conceptual mathematical understanding are broadly recognized. Despite these capabilities, evidence from the studies points to a certain inertia on the part of many teachers to do anything else than use IWBs as large-scale visual blackboards or presentation tools. The emerging view of how to attempt to overcome these obstacles is that there is need for greater attention to the pedagogy associated with IWB use and, more specifically, to stimulate the design of new kinds of learning environments.
\end{abstract}

\section{Introduction}

In recent years, interactive whiteboards (IWBs) have moved from being considered a novelty into a regular part of the equipment of many classrooms, especially in the United Kingdom, and in other countries of Western Europe, North and Central America, South East Asia, and Australia. IWBs provide interesting opportunities for students and teachers alike to interact with digital content in a multiperson learning environment.

This study aims to deliver a critical analysis of the literature on IWBs in mathematics teaching, with a view to identifying strong and weak points and specifying a theoretically and practically relevant research agenda. The review first shortly discusses IWB affordances and presents the focus of the study as well as the adopted methodological approach. Next, we analyse in detail the results of empirical research on the effects of the use of IWBs on learning and students' achievement. Finally, some conclusive observations and reflections are developed, also in relation to the general literature about information and communication technology (ICT).

Technologically speaking, IWBs connect a computerlinked to a data projector-and a large touch-sensitive board that displays the image projected from the computer and allows direct input and manipulation through the use of fingers or styli. Software provided with the boards offers additional functions that improve the facility to control the computer at the touch of the screen [1]. As Beauchamp and Parkinson [2], Kennewell [3], Mercer et al. [4], and others have noted, these additional functions include the following:

(i) drag and drop: moving around screen items to allow classification, processing, comparison, ordering of terms, and so forth;

(ii) hide and reveal: allowing ideas to be shown gradually so that conceptual development takes place, and elaborating the development of hypotheses; 
(iii) colour, shading, and highlighting: emphasising similarities and differences, enhancing explanations, and allowing reinforcement through greater emphasis;

(iv) multiple visualization: matching different ways to present an issue;

(v) multimedia presentation: replicating nondigital technologies such as overhead projectors, slide projectors, and video players;

(vi) manipulation of objects from other technologies and software: displaying objects elaborated in other types of software and operating with them;

(vii) movement or animation: demonstrating principles and illustrating explanations;

(viii) indefinite storage and quick retrieval of material: saving previous work as personal files and using them for revision, support, and further development.

These features, combined with a display large enough for a whole class to see clearly, provide teachers with opportunities for access to a rich blend of diverse, multimodal resources, for manipulation and exploration and for increasing class participation.

As a result, IWBs are claimed:

"to have the potential to enhance demonstration and modelling; to improve the quality of interactions and teacher assessment through the promotion of effective questioning; to redress the balance of making resources and planning for teaching; to increase the pace and depth of learning." ([5], page 2).

Mercer et al. [4] stated that "the IWB allows a flexibility in the marshalling of resources that enables teachers to create interesting multimodal stimuli for whole-class dialogue much more easily than do other technologies" (p. 207).

IWBs have been found to be particularly useful in teaching mathematics. Glover et al. [6] affirmed that an IWB still has the potential to transform mathematics teaching, and in many cases it clearly has done so. The large-scale study by Somekh et al. [7] revealed that with more exposure to IWBs in mathematics pupils on average made greater progress. Mathematics has always been, and is still, a subject of considerable importance in schools; it is also a subject in which educational technologies are frequently employed, in part because the teaching of mathematic topics may greatly benefit from multiple representations and animations, and in part because a great deal of software for mathematics instruction is available [8]. As reported by different authors, in the UK, USA, Canada, Australia, and other countries, IWBs are increasingly being used in mathematics instruction both in primary and secondary education [9-12]. In 2005, a national survey in England found that nearly half of all primary school teachers (49\%) had already made use of IWBs in their mathematics teaching; in secondary schools, $77 \%$ of mathematics teachers used IWBs in their lessons [13].

Often mathematics lessons show a lack of variety, with typical lessons concentrating on the acquisition of skills, the solution of routine exercises and preparation for tests and examinations [14]. In mathematics education, it is commonly claimed that the use of multiple representations and the flexibility to switch between them is an important component in mathematical thinking, learning, and problem solving. Heinze et al. [15] stressed how "instructional environments wherein learners are confronted with multiple representations of a given mathematical concept, principle or situation, and wherein they learn to switch fluently and flexibly between these various representations, are considered as more effective in enabling learners to understand and apprehend mathematical notions and to develop a genuine mathematical disposition than environments that do not emphasize multiple representations" (p. 536).

Given its previously described affordances, IWB technology provides an innovative tool with high potential for mathematics instructional environments. Teachers can use IWBs for modelling mathematical ideas and strategies, demonstrating theorems, explaining difficult concepts, stimulating discussion about relevant mathematical topics, inviting interpretations of what is displayed, and challenging students to apply their mathematics to solve problems [16]. Good practice in mathematics education includes the use of high quality diagrams and relevant software to support learning through, for example, construction of graphs or visualisation of transformations [10, 17]. The IWBs' affordances, especially the capacity to present a wide variety of multimedia resources, the ability for movement and animation to demonstrate principles and to illustrate explanations, the possibility to match different representations (geometrical and algebraic) may favour enhancements in teaching and learning $[8,18]$. Furthermore, mathematics learning is an essentially constructive activity. Learners need to engage in the processes of mathematical thinking: framing and solving problems, looking for patterns, making conjectures, examining constraints, abstracting, inventing, explaining, justifying, challenging, and so forth [19]. In this respect, the interactive affordances of the IWB can be exploited to promote the learners' active involvement in these mathematical thinking processes through the use of a more interactive pedagogy.

Because mathematics education is one of the domains in which IWB technology may be most beneficial and because, consequently, it is one of the domains that has received most attention in IWB research, our literature review focuses on studies of mathematics teaching through IWBs. The main underlying question of this review is whether the use of IWBs in classrooms improves the interactivity in mathematics teaching, and whether this improvement enhances student understanding of basic concepts, encourages idea generation, and better promotes students' achievements.

\section{Method}

The review process followed the three main steps of a systematic literature review [20], namely, retrieval, selection, and analysis of the literature.

Research was identified through authoritative internet sources: ERIC (Education Resources Information Centre), 
Google Scholar, Science Direct, Thomson Reuters Web of Science. Search terms and phrases included Interactive Whiteboards, IWB, and Smart Board (Smart Board is a particular widespread IWB brand) combined with mathematics, mathematical education, and numeracy. The research sought for journal articles, book chapters, proceedings, and doctoral dissertations concerning teaching and learning mathematics in IWB environments. Given the novelty of the field and the aim to obtain a broad overview, the research was rather "open," including different kinds of contributions. Publications about specific didactical practice (for instance a paper by Merrett and Edwards [21] concerning software applications for angles study) or papers pointing at special groups of students (for instance disabled or gifted students) were excluded from the review. The literature search was conducted in English (searches conducted in Italian and French did not identify any relevant results), because the literature on IWBs is mostly in English as educational institutions in the UK and the USA were first to adopt this technology and stems predominantly from research in UK, where IWBs have been used in classroom environments since 1999. In more recent years, IWB use has spread through other countries, such as Australia and some European countries, and a number of studies from these countries are also available and have been considered in this review. Research conducted in England by the British Educational Communications and Technology Agency (BECTA), which monitored the integration and the effectiveness of IWB use in British schools since their adoption throughout the country, was also included in the review. Some special journal issues (Learning, Media and Technology, 32, 3; Technology, Pedagogy and Education, 19, 1; Australasian Journal of Educational Technology, 26, 4) and an edited volume by Thomas and Schmid [22] published in recent years, and providing evidence of the great interest generated by this tool, were also consulted and selected. The search for internet sources and journal annals was limited to publications from the last twelve years (i.e., since 2002), during which time the advancement and widespread use of IWBs has grown rapidly [23].

Studies were analysed with respect to methodological approaches, key findings, implications, and conclusions of each study. The studies were categorized as follows:

(i) large-scale studies that do not rely on (quasi-) experimental methods but use a combination of other methods such as surveys an interviews with teachers and students; classroom observations and statistical analyses of students' attainment (Section 3.1);

(ii) quasi-experimental studies investigating the impact of IWB use on students' gains, either by comparing students with and without IWB use, or by comparing students in different IWB use conditions (Section 3.2);

(iii) case studies (classroom observational studies in one school or a limited group of schools), often integrated with teachers' and students' interviews (Section 3.3);

(iv) contributions reporting interventions of various kinds, aimed at enhancing IWB use, for example, curriculum interventions and workshops that do not fit into one of the three previous categories (Section 3.4).

Table 1 shows the reviewed articles, the education level, the country, type, employed methods, and whether the article was peer-reviewed.

\section{Results}

3.1. Large-Scale Studies. Three large-scale studies were retrieved, two in primary education $[7,18]$ and one in secondary education [17]. All three studies used a mixed method research design including surveys, interviews with both teachers and students, in-depth case analyses, and statistical analyses of students' attainment in national tests.

A large-scale evaluation of the impact of IWBs for the UK's Primary National Strategy's "Embedding ICT in the Literacy And Numeracy Strategies" was conducted by Higgins et al. from Newcastle University (UK). In this project, IWBs were installed in all of the Year 5 and 6 classes in more than 70 primary schools (122 classes) in six regions of England [18, 24]. The evaluation investigated aspects of classroom interaction through a series of structured observations, teachers' weekly records of IWB use, and the impact on students' attainment through their performance in national Key Stage 2 (classes from 3 to 6) tests. Structured observations of classroom interaction were undertaken in 2003, and again a year later in 2004. A total of 184 lessons were observed; the research focused on differences between lessons where teachers did and did not use IWBs for literacy and mathematics and on any changes in patterns of interaction a year later. The research also investigated teachers' perceptions (through individual interviews with sixty-eight teachers) and students' perceptions (through twelve group interviews with students who had been in classes where an IWB had been in use for two years).

Teachers reported using the IWBs in approximately twothirds of the mathematics lessons in 2003 and nearly threequarters of these lessons in 2004. Overall, the interviewed teachers were extremely positive about the impact of IWBs on their teaching and thought that using the IWBs in lessons improved students' motivation to learn. A consistent proportion of teachers (85\%) believed that IWBs would lead to improvements in students' attainment.

Students were also very positive about the use of IWBs; most of the pupil groups interviewed stressed that the IWB helped them to pay better attention during lessons, due to the opportunity for a wider range of resources and multimedia features being used.

In observed lessons, classroom interaction was monitored by logging the number of different types of discourse. The scheme gathered data on teachers' questions (open or closed), whether questions were answered (and by whom), and the types of evaluative response given by the teachers to students' answers. It also recorded pupil initiations in the form of questions and statements. Through a one-way ANOVA test, significant differences were found between lessons that employed IWBs and those not using them. The IWB lessons 
TABLE 1: Key studies included in the review (in alphabetical order of first author).

\begin{tabular}{|c|c|c|c|c|c|c|}
\hline & Authors and year & $\begin{array}{c}\text { Education } \\
\text { level }\end{array}$ & Country & Type & Methods & $\begin{array}{c}\text { Peer- } \\
\text { reviewed }\end{array}$ \\
\hline 1 & Bruce et al., (2011) [9] & Primary & Canada & III & $\begin{array}{l}\text { Classroom observation, students' and teachers' } \\
\text { survey, teachers' interviews }\end{array}$ & Yes \\
\hline 2 & Essig (2011) [41] & Primary & USA & III & Classroom observation, teachers' interviews & No \\
\hline 3 & Glover et al., (2003) [27] & Secondary & UK & III & $\begin{array}{l}\text { Classroom observation, students' and teachers' } \\
\text { survey, teachers' interviews }\end{array}$ & No \\
\hline 4 & Glover et al., (2007) [6] & Secondary & UK & III & $\begin{array}{l}\text { Classroom observation, students' and teachers' } \\
\text { survey, teachers' interviews }\end{array}$ & Yes \\
\hline 5 & $\begin{array}{l}\text { Glover and Miller (2009) } \\
\text { [35] }\end{array}$ & Secondary & $\mathrm{UK}$ & IV & Development of IWB use in classrooms & Yes \\
\hline 6 & Higgins et al., (2005) [18] & Primary & UK & I & $\begin{array}{l}\text { Teachers' survey, teachers' and students' } \\
\text { interviews, classroom observation, test } \\
\text { achievements }\end{array}$ & No \\
\hline 7 & Holmes (2009) [37] & $\begin{array}{l}\text { Pre-service } \\
\text { teachers }\end{array}$ & Australia & IV & Development of mathematical lesson activities & Yes \\
\hline 8 & Jewitt et al., (2007) [30] & Secondary & UK & III & Classroom observation, students' interviews & Yes \\
\hline 9 & $\begin{array}{l}\text { Jones and Tanner (2002) } \\
\text { [26] }\end{array}$ & Secondary & $\mathrm{UK}$ & III & $\begin{array}{l}\text { Classroom observation, students' and teachers' } \\
\text { survey, teachers' interviews }\end{array}$ & Yes \\
\hline 10 & $\begin{array}{l}\text { Kennewell et al., (2008) } \\
{[13]}\end{array}$ & Primary & UK & III & $\begin{array}{l}\text { Classroom observation, students' and teachers' } \\
\text { survey, teachers' interviews }\end{array}$ & Yes \\
\hline 11 & $\begin{array}{l}\text { Lavicza and Papp-Varga } \\
\text { (2010) [39] }\end{array}$ & Secondary & Hungary & IV & $\begin{array}{l}\text { Development of mathematical lesson activities } \\
\text { using geometrical dynamic software }\end{array}$ & Yes \\
\hline 12 & Miller et al., (2005) [28] & Secondary & UK & III & $\begin{array}{l}\text { Classroom observation, students' and teachers' } \\
\text { survey, teachers' interviews }\end{array}$ & No \\
\hline 13 & Miller et al., (2005) [29] & Secondary & UK & III & $\begin{array}{l}\text { Classroom observation, students' and teachers' } \\
\text { survey, teachers' interviews }\end{array}$ & No \\
\hline 14 & $\begin{array}{l}\text { Miller and Glover (2007) } \\
{[16]}\end{array}$ & Secondary & UK & III & $\begin{array}{l}\text { Classroom observation, students' and teachers' } \\
\text { survey, teachers' interviews }\end{array}$ & Yes \\
\hline 15 & Miller et al., (2008) [36] & Secondary & UK & IV & Development of IWB use in classrooms & No \\
\hline 16 & $\begin{array}{l}\text { Miller and Glover (2010) } \\
{[10]}\end{array}$ & Secondary & UK & IV & Development of IWB use in classrooms & Yes \\
\hline 17 & $\begin{array}{l}\text { Miller and Glover (2010) } \\
\text { [38] }\end{array}$ & Secondary & UK & IV & Development of IWB use in classrooms & No \\
\hline 18 & Moss et al., (2007) [17] & Secondary & UK & I & $\begin{array}{l}\text { Classroom observation, teachers' survey, } \\
\text { teachers' and students' interviews, test } \\
\text { achievements }\end{array}$ & No \\
\hline 19 & $\begin{array}{l}\text { Serow and Callingham } \\
(2011)[32]\end{array}$ & Primary & Australia & III & $\begin{array}{l}\text { Classroom observations, field notes, students' } \\
\text { work samples }\end{array}$ & Yes \\
\hline 20 & Smith et al., (2006) [24] & Primary & UK & I & $\begin{array}{l}\text { Teachers' survey, teachers' and students' } \\
\text { interviews, classroom observation, test } \\
\text { achievements }\end{array}$ & Yes \\
\hline 21 & Somekh et al., (2007) [7] & Primary & UK & I & $\begin{array}{l}\text { Teachers' survey, teachers' and students' } \\
\text { interviews, classroom observation, test } \\
\text { achievements }\end{array}$ & No \\
\hline 22 & Swan et al., (2010) [11] & $\begin{array}{l}\text { Primary and } \\
\text { secondary }\end{array}$ & USA & II & Students' attainments & No \\
\hline 23 & $\begin{array}{l}\text { Tataroglu and Erduran } \\
(2010)[25]\end{array}$ & Secondary & Turkey & II & Students' attitude survey and interviews & Yes \\
\hline 24 & $\begin{array}{l}\text { Torff and Tirotta }(2010) \\
{[8]}\end{array}$ & Primary & USA & II & $\begin{array}{l}\text { Students' attainments, teachers' and students' } \\
\text { interviews }\end{array}$ & Yes \\
\hline 25 & $\begin{array}{l}\text { Wood and Ashfield } \\
(2008)[33]\end{array}$ & Primary & UK & III & $\begin{array}{l}\text { Classroom observation, students' and teachers' } \\
\text { survey, teachers' interviews }\end{array}$ & Yes \\
\hline 26 & $\begin{array}{l}\text { Zevenbergen and } \\
\text { Lerman (2008) [12] }\end{array}$ & Primary & Australia & III & $\begin{array}{l}\text { Classroom observation, students' and teachers' } \\
\text { survey, teachers' interviews }\end{array}$ & Yes \\
\hline
\end{tabular}


contained more whole-class teaching and less group work. The lessons involving IWBs had significantly more open questions, answers from students, probes, evaluation, and general discussion. Most of these differences were only observed after the IWBs had been in use for a year. The IWB use also contributed to a faster pace in the lessons (measured as increase in the total number of interactions between the teacher and students in these classes). In terms of the impact on students' attainment, however, the IWBs appeared to have a negligible effect. Compared with other schools nationally, the students in the IWB pilot schools performed better on national tests in mathematics in 2003. Though statistically significant, the extent of the difference was small, and no difference was found in performance on national tests for the pilot project schools in 2004.

The second large study of primary education in literacy, science, and mathematics was conducted by Somekh et al. [7]. The study concerned 4,116 students from Year 3 to Year 6 (aged between 7 and 11) in 172 classes in 97 primary schools, and 3,156 students in Years 1 and 2 (between 5 and 7 years old) in 160 classes in 96 primary schools, in 20 local authorities in England. The research was carried out between September 2004 and December 2006, and included classroom observations, logs of interactive whiteboard use kept by teachers, IWBs coordinators' survey and teachers' survey, and evaluation of students' achievements. The research involved the collection and analysis of a large body of quantitative and qualitative data. Multilevel modelling analyses linked the length of time students have been taught with IWBs to greater progress in national test scores. The multilevel modelling approach was capable of investigating the impact of IWBs and the extent to which this may differ for specific groups of children. Interestingly, this study is the only one that also examined differences among students with respect to different levels of attainment. It was found that IWBs benefited averagely attaining students and highattaining students in that they made greater progress with higher exposure to IWBs in mathematics, whereas IWBs had little effect (but certainly not a detrimental effect) upon the progress in mathematics of low-attaining students. In evaluating their findings, the researchers concluded that the use of an IWB increases the level of children's engagement with learning activities.

Within the context of this second large-scale study, the researchers also observed nine teachers from seven schools. The teachers were chosen on the basis that in national tests in 2005 their classes had shown progress between the baseline and posttest outcomes. This enabled the evaluators to observe classrooms where the use of IWBs had become fully embedded in teaching and learning through use for more than two years. Over the period of the evaluation, the use of IWBs across the curriculum had increased. A huge majority of interviewed teachers felt they had adopted new teaching practices as a result of having an IWB. In the observed classrooms many teachers had made radical changes to their lesson planning, creating or accessing their own resources, and storing them in either personal or shared areas on the school's server. Research findings from classroom observations showed that IWBs aid the teaching of difficult, abstract and complex ideas, that the ambience of classrooms in which IWBs are used is more cooperative and "sharing," and that there are very positive effects on the attention, attitude, and motivation of students in classes with IWBs. Authors stressed how IWBs introduce more possibilities for positive interactivity between the teacher and the learners, which is an essential pedagogical component.

The third large-scale study, on secondary education, by Moss et al. [17], evaluated the expansion of the use of IWBs in mathematics, science, and English into all secondary schools in London. The objectives of the research were to assess the impact of IWB use on teaching and learning, teacher/pupil motivation, pupil attendance and behaviour, and outcome attainments in core subjects. Like the two previous investigations, the study used a mixed methods research design: in-depth case studies, with structured observation and video recording of lessons (27 classes), teacher's surveys, and group interviews with students from each of the classes observed. Researchers also conducted a statistical analysis of students' performances (national test scores in English, mathematics, and science for students aged from 11 to 16).

The authors reported that IWB use varied according to the teachers and subject areas and that although the novelty of the technology was initially welcomed by students, the increase in motivation appeared short-lived. Authors' analysis of in-depth case studies showed that the differing curriculum demands of mathematics, science, and English affected the way in which teachers interpreted and used the facilities afforded by IWBs. For instance, the use of IWBs to visualise or dynamically represent abstract concepts in new ways had immediate relevance in mathematics and in science, but to a lesser degree in English. In both interview and survey responses, it became apparent that some of the IWB features have a special usefulness in mathematics lessons. The use of colour, shading, and highlighting, capability for multiple visualization and animation, and dynamic applications to reinforce conceptual learning were the most frequently mentioned aspects of the IWBs that students and teachers were positive about. Mention was made of the clarity and accuracy of diagrams, animations, and use of specific software (graphing or geometrical) that could more accurately replicate the object under discussion in ways that teachers' "freestyle" drawings could not.

In their analysis of recorded lessons, Moss et al. [17] observed that the use of an IWB as such does not automatically alter the dynamic of whole class teaching in secondary mathematics. Teachers conceived interactivity in different ways (technical interactivity, i.e., use of IWBs technical features, physical interactivity, i.e., students using the board, and conceptual interactivity, that involves a deeper understanding of concepts) and this influenced the pedagogy observed in the classrooms. Observations showed that when use of the technological tools took precedence over a clear understanding of pedagogic purposes, IWBs were used to reinforce whole class teaching from the front, with limited dialogic episodes and little student interaction. Where best practices were observed, teachers had consciously set aside time to reflect on the most appropriate use of the technology in their pedagogy and more spaces for interactive work, 
discussion, and extended dialogue were opened up. These lessons were characterized by a move away from only using IWB features such as drag-and-drop or hide-and-reveal, to the use of dynamic demonstration to reinforce learning and creating opportunities for talk supported by technologyenabled manipulation of elements on the board.

Statistical analysis explored the impact of the increase in IWB acquisition on students' performance. The data were used in separate sets of regressions to analyse whether changes in the "value-added" achieved at school level, at teacher level and by departments between 2003/04 and $2004 / 05$, could be attributed to the increased number of IWBs per student between the two years. Due to technical problems, the analysis was limited to just over 30 schools (9 per cent of London schools), and around 9000 students. Overall, the statistical analysis failed to find evidence of any impact on students' attainment (measured in national test scores) in the academic year 2004/5.

3.2. Quasi-Experimental Studies. The three large-scale studies presented above do not lead to conclusive claims about students' cognitive attainments in mathematics. Whereas the study by Somekh et al. [7] found an increase in students' performance, the other two did not reveal any appreciable rise. The three studies presented in this section are (quasi)experimental studies and substantially confirm the results of the large-scale studies, namely, that increases in attainments, where observed, are small and weakly significant.

A first quasi-experimental study was carried out by Swan et al. [11]. The research took place in a small city school district in northern Ohio, USA, and involved students enrolled in eleven elementary schools, three junior high schools, and one alternative school in 2006-2007. A total of 31 classes in which teachers used IWBs for mathematics instruction in grades three through eight (age 7 to 15) were compared with 43 classes in which teachers did not use IWBs. The state Ohio Achievement Tests (OAT) measure students on what they know and are able to do in various subjects and are applied in grades three through eight; the results given here come from a comparison of OAT scores between students whose teachers used IWBs in mathematics or English language in those grades, and students whose teachers did not. The results of this study show a slight achievement increase amongst students whose teachers used IWBs for mathematics instruction. The increases were statistically significant only in mathematics, and not in other subjects.

Torff and Tirotta [8] conducted another quasi-experimental study to determine the extent to which teachers' attitudes about the use of IWB technology (assessed by a teachers' survey) was associated with upper elementary students' self-reported level of motivation in mathematics. The study involved 32 teachers and 773 students in $3 \mathrm{rd}$, 4th, and 5th grade classes in a single school district in suburban New York City (USA). The sample was divided in a treatment group, exposed to IWB lessons, and in a control group taught without IWB. Analysis of covariance (ANCOVA) was performed to determine the extent to which students' attitudes about mathematics differed across groups (treatment versus control), controlling for grade level, students' gender, teachers' attitudes about IWB, teachers' years of teaching experience, teachers' gender, and teachers' level of educational attainment. The variable "teachers" attitudes about the IWB' made a significant contribution to the variance in students' self-reported motivation level in mathematics, although the effect was quite small $(P<0.05$; partial etasquared $=0.02$ ). The remaining four independent variables made no significant contribution to the variance in students' motivation level. In the group exposed to IWB lessons, teachers' positive attitudes about the IWBs were associated with slightly higher levels of motivation among their students; in other words, teachers who strongly supported using the IWBs (and most likely used the technology well) produced larger motivational effects in their students, nevertheless the motivation-enhancing effect of the IWBs found in this study was very weak. Considerations by the authors stress the need to examine in greater detail how the IWB is used in the classroom and what kinds of results these various uses produce.

Finally, the research by Tataroglu and Erduran [25] was done to determine the attitudes and to evaluate the views of 10th grade students towards IWB use in mathematics classes as part of a quasi-experimental study. The participants were 60 students from a public school in the city of Izmir, Turkey. This group's lessons were covered using an IWB for five weeks. Quantitative data was collected using a questionnaire developed by the researchers "Attitude Scale Towards Interactive Whiteboard in Mathematics Classes." In addition, an interview form was used to collect qualitative data. Students were introduced to this new technology for the first time and used the IWB for a short period. The authors found that the use of the IWB increased students' interest and motivation and focused their attention. Students' attitudes towards IWBs were positive: more than half of the students stated that they would like to do all their math lessons using the IWB, as it provided the advantages of saving time and providing visuals. Amongst the negative features, students mentioned writing because it was difficult to write on the IWB, and there was a delay between something being written and appearing. According to some students, the fast pace of the lessons in which the IWB was used created a negative situation.

3.3. Case Studies. While large-scale and small-scale studies of outcome variables were relatively few, a larger number of case studies and observational studies were carried out by different authors. These studies are empirical enquiries that investigate the IWB use in classroom context, have a smaller scale (one school or a limited group of schools) than the large-scale studies previously presented, are not quasiexperimental studies, and focus on the implementation of IWBs in mathematics teaching and learning rather than on general results. All the studies in this group are qualitative studies, based mainly on classroom observations. Teachers were observed while teaching with IWB support, trying to identify IWB features, and teaching strategies that improve effectiveness and interactivity in mathematics lessons. Observations were often related to frameworks elaborated by the 
research team together with the observed teachers, and not always these frameworks were specified in detail. Therefore, in many cases it was not possible to retrieve information on the quality of instruments used, the appropriateness of methods applied, and the quality of the results. Classroom observations were often combined with teacher and student interviews.

Jones and Tanner [26] studied eight mathematics teachers from four secondary schools in the south of Wales, UK, forming a teacher inquiry group to qualitatively research the impact of introducing whole-class interactive teaching strategies into their own practice with IWBs. Lesson observations, interviews with teachers, and discussions at the group meetings, however, indicated that the implementation of the strategies varied significantly between teachers. The main features recognised within the classroom dialogue included the extent to which students were encouraged to reflect on their mathematical knowledge and the ways in which teachers were able to scaffold students' learning. Findings from the study showed that the quality of the interaction varied between teachers. The quality was found to be dependent on the opportunities created for reflection and on the quality of the questions posed. Opportunities for reflection and quality of questioning needed to be developed to ensure interactivity in mathematics teaching when using IWBs.

Glover et al. [27], within the Cognitive Acceleration in Mathematics Education (CAME) project, observed mathematics teachers from 12 schools working in partnership and using IWBs; the teachers were all competent in IWB use. Six lessons about fractions, based on the mathematics National Curriculum for Year 7 (students aged 11-12), were elaborated and used with students. The aim of the project was to establish whether-and if so, how-the use of the IWBs promoted learning in mathematics. Evaluation was by questionnairebased pupil and teacher surveys, teacher measurement of enhancement in learning, teacher interviews, and observed lessons. Activities included shading fractions of shapes, equivalent fraction problems, use of a fraction wall (a visual tool that helps to understand fractions equivalence), and fractions on lines of varying length. In all lessons, some attempt was made to recognise and respond to varying learning style needs. The lesson structures demonstrated a variety of visual representations of concepts and examples. In part this came from the use of visual, verbal, and sequential materials, but in some lessons teachers used alternative representations of ideas, showing fractions in different ways, or using fractions of a shape to illustrate a numerical statement. Teachers were using the IWBs mainly during the phases of introduction and demonstration while during the exemplification phase IWB practice varied; some teachers did not use them at all, while others used them to reinforce learning and understanding. The authors concluded that teachers' employment of IWBs was still in its infancy, not from the point of view of technical interactivity using the IWB's functionality, but rather with respect to the pedagogical interactivity.

Miller et al. [28] reported the findings of research undertaken for BECTA (British Educational Communications and Technology Agency). The research was conducted in secondary schools observing and video recording 10 mathematics teachers and 13 modern foreign language teachers for at least one lesson (some for more), and then interviewing them using a semistructured interview format. The key question was "What are the essential features of interactivity, intrinsic to the use of IWBs that make them more effective than current similar presentation media (whiteboards, overhead projectors, computers with data projectors)?" ([28], p. 4). The analysis suggested that teachers progressed through three stages according to their level of interactivity:

(i) supported didactic: where IWBs are used as visual support, the teacher tends to direct teaching; the focus is on the teacher and students are receptors;

(ii) interactive: where IWBs are used as an occasional stimulus and for demonstration with lively content, students are encouraged to question and develop ideas when the IWB is in use, and the teacher promotes discussion but the style is still directive;

(iii) enhanced interactive: where IWBs are used to prompt, explain, develop, and test concepts throughout a lesson, combining differing modes of learning (verbal, visual, and kinaesthetic approaches); the teacher uses IWBs for most lessons, exploiting their complexity with fluency to stimulate and develop ideas for and with students.

A feature of enhanced interactivity was the way in which the IWBs were being used to underpin lesson structure and to enhance the way that students were thinking. The authors analysed the structure of a lesson at enhanced interactivity level. First, objectives were set, sometimes revisiting earlier IWBs slides. Next, "a bright and lively starter would be used to stimulate interest, to offer a chance for brainstorming as a bridge to the main part of the lesson or to revise necessary associated learning." ([28], p. 17).

In the main part of the lesson, the IWB was the focus of much activity; it was effectively used to give clear models in illustration, explanation, sequencing of ideas and the development of main principles. During this part of the lesson, the authors stressed the importance of understanding and using questioning: teachers used very few closed questions, and moved quickly to open questioning. IWB multiple visualization affordance appeared to be of great benefit when the style of questioning shifted from closed questions to those that required reasoning in the development of a process or the building up of an argument. Lessons concluded with a plenary session involving the recall of earlier examples and previously studied material to ensure understanding and form the basis of extension work. In mathematics, this was usually achieved by posing a cognitive question as both a conclusion and a bridge to the next lesson.

The key feature was found to be planning and preparation. Teachers at the enhanced interactive stage tended to plan for cognitive development. They tended to use clear visual representation of concepts and ideas, often illustrating them in different ways by taking into account the capabilities of the IWBs. IWB features were used to demonstrate the potential 
for abstract knowledge to be physically and verbally realised and then manipulated by teachers and students, and for this process to be displayed and so made available to the whole class.

Miller et al. [29], in a study conducted by a team from Keele University in 12 local secondary schools in England, video recorded and analysed mathematics lessons of those teachers who were making extensive use of IWB technology. Analysis was conducted referring to a number of variables (the timeline and activity sequence in each lesson; classroom management issues; the nature of IWB techniques used within the lesson and their perception by pupils; an assessment of the teaching style used in the lesson; teacher and pupil technological fluency; identification of practical and pedagogical issues; enhancement resulting from IWB use within a framework of pedagogic elements; the extent of "on task" work when the IWB was the focus of attention; the percentage of the lesson when the IWB was the focus of teaching and learning; the contribution of IWB use to conceptual and cognitive development), but the analytic tools used in the study are not specified. The authors observed that there are canonical visual representations and demonstrations in the mathematics curriculum which the visual features of IWBs, such as drawing software, can enhance, leading to new forms of display and collective analysis. For teachers working at the enhanced interactive stage, there was a tendency to use activities that featured several techniques and to employ a combination of commercially produced materials and materials developed by the teacher. These lessons had greater pace and tended to use the IWB as the focus of all activity.

According to Miller et al. [29] the main features for encouraging learning are the intrinsic stimulation provided by the combination of the visual, kinaesthetic, and auditory paths to learning, the sustained focus maintained throughout the lesson by the teacher's management and "orchestration" skills, and stepped learning through constant challenges with frequent assessment of achievement as a stimulant to further involvement. The potential enhancements in learning originate from the design through which teachers structure the learning processes so that the IWB may reveal its affordances.

Other authors gave examples of the different practices of using IWB technology in classrooms. Jewitt et al. [30] observed in 2004-2005 a number of mathematics lessons in 27 classrooms of secondary schools and examined how resources were articulated and mediated in the classroom through teachers' lesson design. No quantitative data were reported; the study was based on qualitative observations. In some of the observed lessons the IWB was used in much of the same way as a traditional blackboard, while in other lessons IWBs were used in an advanced manner. For example, the topic of one lesson was algebra and factorisation; the teacher used a prepared flipchart text. The main slide showed the black outline of a square divided into sections and two sets of shapes: a yellow square and a series of four differently coloured shapes (two brown rectangles of the same size, and two differently sized and coloured squares) which, when arranged, filled the yellow square and outline. The teacher taught from the back of the class. The black outline of the square displayed on the board acted as a guide for the initial arrangement of the shapes; students then suggested and showed alternative arrangements of the four shapes within the square. The students used image, colour, and movement to explore factorisation through manipulation of the different shapes and visual checking of the fit between the series of shapes and the large yellow square. The visual and dynamic text offered the students a different representation that was central to the learning task. Images did not supply a similar version of a concept; they provided a different representation of it. The multimodal representation offered the possibility to make connections between the specialised knowledge of mathematics and the everyday knowledge of space and design. The whole-class teaching method was designed to enhance and create spaces for interactive work. Discussion and extended dialogue were opened up by the teachers' use of the IWB. The board was used to display students' processes of thinking and ideas, realised through discussion and student participation in the lesson. The teacher and students together created the texts.

Another study by Miller and Glover [16] was carried out in the mathematics departments of seven English secondary schools during the two terms following the installation of several IWBs within the department. Qualitative analysis concerned the level of the lessons (classified by the researchers as "supported didactic," "interactive," and "enhanced interactive") and changes in these levels from the first to the second phase of observations. The seven schools were drawn from three localities and comprised a range of rural, semirural, and urban contexts. In the schools, IWBs were installed in spring 2005. All schools were visited in the weeks shortly after the installation of equipment (September 2005) and then again in early January 2006. During the initial visit, 42 complete mathematics lessons were recorded, and 46 lessons were recorded during the second visit. One to three lessons were observed for each teacher. The main concern was ascertaining participants' perceptions of their induction into the use of IWB technology (over this period of two terms) and to see whether there was any relationship between the induction experience and the impact that this had on classroom practice. Evidence suggested that the technology was either installed with minimum IWB training and a general technological and pedagogical introduction or installed with continuous mentoring from advisors. In those schools characterised by the latter pattern, there appears to have been a more rapid progression from traditional to interactive teaching approaches; the authors' conclusion was that effective IWB teaching requires continuing professional development and specific personal coaching with a consideration of both interactive whiteboard techniques and pedagogy.

Glover et al. [6] involved teachers drawn from mathematics and modern foreign language departments in secondary schools in a study that was undertaken in 2003-2004. This study presented interesting findings and reflections about elements that may foster an enhanced interactive pedagogy: planning for cognitive development, clear visual representation of concepts, activities that encourage an active, thinking approach, illustrating concepts in different ways, 
sequencing, and immediate feedback. Regarding mathematics, 24 teachers from 20 different schools were involved; arrangements were made to video record 34 lessons (some teachers agreed to be video recorded with a second teaching group and so were observed twice). Structured interviews were undertaken with all participating teachers. Inquiries referred to training, perceptions of the problems inherent in IWB usage, development of IWB competence (both teacher and student), changing approaches to classroom management, lesson content, and changes in pupils' conceptual and cognitive understanding. Video recorded lessons were analyzed with respect to the lesson structure (timeline and activity sequence, nature of IWB techniques used, assessment of the teaching style used: on a range from didactic to experiential), classroom management issues (group arrangements when pupils were at their tables or at the IWB, use of other teaching materials such as textbooks and worksheets, and their integration with the IWB) and IWB impact on effective teaching (technological fluency of teachers in the preparation of materials and IWB use, students' fluency in IWB use, impact on conceptual learning and on cognitive development in relation to achievement of objectives, use of different ways to address various learning styles to enhance understanding, and the occurrence of episodes of recall and review). Results from observations were discussed with the teachers' team at a qualitative level.

Three approaches to teaching (supported didactic, interactive, and enhanced interactive [28]) were evident to a greateror-lesser extent in each of the observed lessons. In the lessons classified as showing enhanced interactivity, some common features were identified:

(i) lesson preparation: technology required teachers to plan with greater precision than in traditional teaching approaches;

(ii) lesson structure: the need for precise lesson preparation meant that effective teachers maintained a structure which offered opportunities for cognitive growth through reflection;

(iii) storing and editing lesson: using an IWB continuously allows teachers to save and reuse resources. Saving materials as the basis of future lesson planning meant that basic lessons could be refined from class-to-class or year-to-year, in the light of changing students' needs and context.

Also this study stressed that it is the quality of the teaching that ensures progress and that the IWB by itself does not guarantee it. The authors point out the need for teachers to have time for developing their technological fluency, and then for incorporating the IWB into their teaching. Only once teachers get skilled in using the technology, they can improve the value of the IWB as a pedagogical tool.

Kennewell et al. [13] referred to an Interactive Teaching and ICT project (Swansea School of Education-Wales, UK) conducted in 2005-2007 in juniors schools, with students aged between 9 and 11. Central to the design of the project was the observation and recording of typical lessons using IWBs taught by the participating teachers (about forty teachers), followed by video-stimulated reflective dialogue between the teacher and their partner researcher. The framework used for the analysis was intended to allow for comparing wholeclass, group, and individual activities involving the IWB, and drawing conclusions concerning the relationship between technical and pedagogical interactivity. The teachers watched the recording of the lesson and selected some episodes for discussion during the reflective interview which was normally held a few days later. Students were also interviewed about the lessons when it was possible. The lesson notes and reflective dialogues were analysed in terms of the goals, the activities, the perceived learning, and the orchestration of the affordances and constraints of the setting in order to achieve the goals of the participants. The study presented a detailed case study. The lesson observed was in mathematics, concerning skill in addition and subtraction, with a class of 29 students. The lesson comprised four phases: the initial phase was a whole-class activity concerning the familiar idea of placing directed numbers in order on the IWB; the main teaching phase was another whole-class activity, which extended the learning to calculations of differences between directed numbers; the third phase involved group/individual work on activities similar to those in the second phase; and the final phase was a plenary session in which the teacher helped the students to reflect on and formalize the ideas that they had been developing during the previous phase. Through a detailed analysis of the four phases the authors found that the influence of the IWB was important. The teacher was skillfully orchestrating the abilities of the students, together with the dynamic visual and tactile features of the IWB display. The IWB acted as a shared resource for the class and, in fact, only the students interacted with it directly.

Beauchamp et al. [31] used a musical metaphor to describe teaching approaches in mathematics classrooms using IWBs. According to the authors the IWB could be considered as an instrument that the players (the teachers) have at their disposal, additional to the more traditional ones of voice, pen/paper, board, and so on. Some instruments will be better quality than others, some players will have a greater skill level than others, and the role of the orchestrator in musical genres is to try and draw the best from the instruments and players at their disposal by allowing varying degrees of freedom within a structured environment. To illustrate this metaphor a teacher was observed using IWBs to teach a class of 13 - to 14 -year-old students about reflection. The software allowed shapes and mirror lines to be drawn and dragged on a grid and generated reflections in specified lines, together with construction lines if required. The lesson started with a triangle displayed on the IWB. The class was asked to discuss in pairs and predict the position of the reflection. Each suggestion was considered in turn, with students being invited to the board to demonstrate their ideas. The teacher asked probing questions about students' reasoning and focused attention on salient features and limitations of the strategies. Finally, the software was used to confirm the position of the reflection under the lines drawn by students, and the construction lines were inserted. In the discussion that followed, "the teacher orchestrated the contributions from a range of voices, in a complex dialogue 
that summarised the learning that had occurred. At this stage, the orchestration demanded improvisation from students as well as the teacher in a cumulative dialogue" ([31], p. 148).

Serow and Callingham [32] presented findings of a project that considered the implementation of IWB technology in three Australian primary mathematics classrooms (students 5 to 12 years of age) within a one-year period observation. The study analyzed the teaching strategies adopted by the three teachers as they embarked on the use of IWB technology as an integral component of their mathematical class activities. Data sources included classroom observations, field notes, and students' work samples produced using IWB technology. In their observations the researchers found three levels of teacher use of IWB technology: use as blackboard substitute, apprentice user, characterised by use of a wider range of the tools provided by the IWB, and initiate user, aware of an advanced IWBs use to enhance pedagogy. Only at the last level IWB technology as a teaching tool promoted studentcentered mathematical activities. From the study it appeared important to engage students not only in technological affordances but in interesting and challenging mathematical tasks.

Not all the case studies show enhancement of interactive work. Wood and Ashfield [33] observed in England ten whole-class lessons in which IWBs were used; five in literacy and five in numeracy, in five primary schools. In addition to these observations, interviews with the respective class teachers and focus group discussions with students provided qualitative data regarding perceptions of IWB technology and their use within the classroom. The authors noted that in many ways the functionality of the IWBs could be viewed as a modern technological version of the traditional blackboard. Observations indicated that teachers did not seek to engage students in higher-level thinking through process-oriented discussion, and the students generally took a somewhat passive role as learners. They seemed to be engaged by the colourful graphics and the movement of visual elements, but opportunities to develop a more interactive approach, stimulating discussion through open and probing questioning, were not fully exploited by the teachers. Effectively, in case multimedia resources and materials were used to replace the teacher through the display and transmission of information, learning appeared to be a matter of routine, with limited opportunities for interaction and discussion.

Zevenbergen and Lerman [12,34] observed 15 classrooms from the upper primary sector using IWBs over three years; the study was part of a much larger study in Australia (Queensland and Victoria) concerned with the ways technologies (ICT) were being used to support mathematical learning in the middle years of school, and comparing classrooms using ICT with classrooms not using it. Grounding on their observations the authors concluded that the use of IWBs actually reduced the quality of mathematical learning, and offered little autonomous/independent learning opportunities for students. Moreover, although IWBs offer affordances not possible in previous media, the overall prevailing pedagogy was similar to more traditional ways of teaching. For the analyses the authors used a number of categories involving four dimensions dealing with the quality of learning: intellectual quality (e.g., deep understanding, substantive conversation); relevance (e.g., knowledge integration, problem-based curriculum); supportive school environment (e.g., social support, self-regulation); recognition of difference (e.g., inclusivity). Classrooms using IWBs scored substantially lower than classrooms that did not use them in the two dimensions which related to the intellectual quality aspects of mathematics learning. Although there were instances in which the IWBs made a rich introduction to aspects of mathematical language possible, the data indicated that, from the pedagogical point of view, their effectiveness may be somewhat limited.

Finally, Bruce et al. [9] conducted two case studies in Ontario (Canada), in mathematics classrooms with teachers of children aged 10 to 12 , collecting data during 8 months. Their aim was to identify how and why the IWB was a productive tool that impacted student learning in mathematics. To do this, the authors looked in the course of the lessons for "significant learning moments", that is, productive instances, in which the use of the IWB is essential for the construction of ideas and conceptual understanding and has a clearly positive impact on student understanding. These significant learning moments are in contrast with reproductive instances, in which the actions on the IWB could be realized in other ways, and with problematic instances, in which technological glitches may actually interfere with learning.

In their count of IWB use instances by teachers and students the authors found $89 \%$ of productive instances, $2 \%$ of reproductive instances, and $9 \%$ of problematic instances. Productive uses abounded when the teacher used a dynamic IWB feature such as a mathematics content tool, internet link, or interactive program, or when teachers provided opportunities for students to do the same. Researchers were surprised with the lack of reproductive instances of IWB use, particularly because reproductive use that supports existing traditional pedagogy is considered a primary type of use in the United Kingdom.

Conclusions by the authors stressed that IWB facilitated positive learning moments for students due to facilitated shared experience: students had the ability to view multiple solutions and solution strategies on a large screen (for collective viewing and discussion) with the support of software tools that illustrate mathematical thinking dynamically. In this way, the IWB operated as a tool to support co-construction of mathematics ideas, supporting simultaneously the creation of a collaborative learning environment.

3.4. Various Contributions. This last section presents a quite varied collection of papers that describe curriculum interventions or provide suggestions for supporting teachers using IWBs in classroom practice, the implementation of external software in combination with IWBs, and discussion contributions to improve teachers' professional development with respect to the use of IWBs.

An IWB research in secondary mathematics teaching was undertaken over two years by a team of teachers working with the Keele University Interactive Whiteboard Team, led 
by Miller et al. [35, 36]. The research focused on pedagogical activities integrated with IWB use, and on curricular content, which was often neglected in other studies.

The study combined a curriculum intervention, involving the development of software and pedagogical topic guides designed to exploit the interactive potential of the boards with an evaluative study of these materials in use. The team created, tested, and finalised a set of materials and resources which would be usable as a stand-alone resource to help mathematics teachers to develop and adapt their pedagogy in order to use IWBs more effectively and efficiently. Methods for the evaluative study of designed materials included classroom observation, teacher and pupil surveys, and two attainment tests, designed to assess the impact on pupil learning. The team proposed an interactive way of working with the IWBs integrating learning activities that might start from work on the IWB (i.e., at the board) or from a deskbased activity (on the desk) or from a concept, idea, or learning objective (in the head). All lesson activities were integrated into an interactive (rather than presentational) whole and orchestrated using the IWB software as the means of storing and organising all the electronic resources for the lesson, facilitating students' interaction with the teacher, the IWB and with each other. In their report, the authors stressed the need for a further range of IWB materials and didactical resources to be developed that reflect the nature of their intended interactivity.

Holmes [37] examined the assessment tasks of a sample of Australian mathematics preservice teachers; the preservice teachers had to plan effectively to integrate IWB features into their mathematical lessons. In teachers' perceptions the primary benefits of the technology were related to the ease with which visual images in the form of diagrams, pictures, links to websites, and animations can be incorporated. In Holmes' opinion, the dominant transformative feature of the IWB technology is its potential to engage students with varied visual representations and virtual manipulatives which can aid conceptual understanding especially for mathematics topics that are traditionally presented more abstractedly. Of the mathematics topics chosen by the preservice teachers, it is interesting to note that only five of the thirteen topics (tessellations, similar figures, surface area, constructing triangles, and circles) involved subject matter that would traditionally lend itself to visual representation. The remaining eight topics (algebra, geometric series, limits, complex numbers, probability, fractions, decimals, and factorising quadratics) would traditionally be considered to be heavily symbolic, either numerically or algebraically. However, the lesson activities developed for these topics involved several visual aids, such as algebra tiles, colour matched symbols, and links to animated applets.

In a discussion piece on teachers' professional development in IWB use, Miller and Glover [10] pointed to the need for teachers to share IWB experiences (and associated software) in introducing mathematical concepts and then to evolve guidelines for professional development work within school departments. In these authors' opinion, a teacher must become IWB technology-proficient before he can attain the Eureka moment, that is, to change the way in which the affordances of the IWBs can be exploited to prompt more effective learning through use of a more interactive pedagogy.

In another paper Miller and Glover [38] reflected on the development of pedagogy by mathematics teachers within a secondary school in England, retracing the history of IWBs introduction. They related this development to the enhanced understanding of IWB use at the beginning as a presentational and motivational support but successively as the ground for more effective conceptual and cognitive learning by the students. The authors pointed to the experience of teachers within the school, supported by a research group at Keele University (UK) and stressed the importance of the integration of the IWBs in the planning of mathematics lessons, suggesting that new approaches may provide potential for further gains. One example was to use the dynamic and "replay" facility offered by the IWBs to explore students' conjectures and misconceptions.

The role of IWBs as tools that support external software is also emphasised by Lavicza and Papp-Varga [39]. The authors conducted several workshops with teachers about the use of GeoGebra (one of the most widespread geometrical dynamic software) in combination with IWBs in Hungary. The dynamic geometry software Geogebra and plays often an important role during the mathematics lessons. As stated by Straesser [40], dynamic geometry software widens the range of possible activities and provides an access route to deeper reflection and more refined exploration and heuristics than in paper and pencil geometry. Utilizing the methodology of a design experiment, training materials and approaches were continuously improved, based on participants' feedback and comments. The authors noted how the IWB environment adds interactivity between the teacher, the materials, and the students compared to projected images of GeoGebra worksheets.

In a doctoral dissertation Essig [41] examined the influences of a professional development program that focused on IWB features and integration methods teachers could use for mathematics instruction. The qualitative case study was conducted with a group of three elementary teachers in a public school in New York (USA). The author observed the teachers during a period of ten weeks, in three phases: before, during, and at the end of the professional development program. Data included interviews with the teachers, classroom observations, and copies of the IWB lessons (recordings of the activities at IWB, recorded by the appropriate IWB tool). The purpose of the study was to understand how the professional development program influenced changes in teachers' pedagogical practices, changes in IWB integration in the lessons, and changes in teachers' perceptions of student learning.

Findings showed some significant modifications in teachers' pedagogical practices. First, teachers designed IWB lessons with a higher level of organisation (increased scaffolding), embedding in them several multimedia features. Second, from the use of IWB as a mere presentation tool teachers began to implement the IWB for the purposes of engaging and interacting with students, incorporating students' activities and including students' using IWB tools. As for teachers' perceptions of student learning, in the last 
phase they believed that the IWB had a positive impact on student learning. Nevertheless, according to the author, it is unclear whether these perceptions were based solely on the integration of the IWB or to lessons design that were more student-centred.

3.5. Summary. This literature review provides a range of evidence of the value of IWBs in mathematical education. The studies reviewed offer a wide view of IWBs' affordances, of the more interesting didactic practices, and of the difficulties of embedding this new technology in the classroom.

The overall picture that emerges from this IWB literature shows benefits and limitations of their potential in mathematics teaching and learning. IWB affordances, listed at the beginning of this review, are highlighted in many of the reviewed studies. IWBs are easy to integrate into the work of the class, and teachers are actually increasing their use in the daily classroom mathematics practice [17]. Affordances most commonly cited in literature $[6,7,18]$ relate to IWBs' flexibility and versatility; multimedia/multisensory presentation; planning and saving lessons.

The large-scale studies $[7,17,18]$ present a large overview of the IWBs usage both in primary and in secondary schools. A range of methodological tools was used to evaluate the impact of IWBs on teaching and learning: classroom observations, IWBs coordinators' surveys and teachers' surveys, pupils' surveys, evaluation of students' achievements. The studies are of great interest for the large amount of data, the quantity and the quality of provided information about IWB affordances, teachers' and students' perceptions, student attainments in national tests, and so forth. Nevertheless they are generally rather dated, as they were all conducted between 2003 and 2005.

The studies that dealt with students' cognitive outcomes in mathematics, both large-scale studies and quasiexperimental studies, do not lead to conclusive claims. Indeed, few studies - actually, only four-dealt with this issue and two of them $[7,11]$ found a statistically significant, though small, increase in students' performance in mathematics, whereas the other two $[17,18]$ did not reveal a significant improvement in students' attainments. As pointed out by Higgins et al. [23], the link between IWB use and achievements is generally very feeble, and the research literature has not yet demonstrated that IWBs have a significant influence on learning attainments. From the point of view of affective outcomes, the positive effects of IWBs on students' motivation and interest are highlighted by, amongst others, Tataroglu and Erduran [25], Higgins et al. [18], and, to a lesser extent, Torff and Tirotta [8].

The case studies stem from heterogeneous backgrounds and include a variety of methods. In the course of the years the research focus of these case studies moved from the novelty effect of technological innovation to the need for developing an adequate IWB pedagogy. Some of the studies are especially interesting in that they analyse the features of enhanced IWB learning environments and in proposing the design of a new pedagogy $[6,13,31,33,35]$. Some other studies $[9,29]$ lack a clear observation and analysis framework, and this issue might limit conclusions made from the observations. Generally, the methodological design of the case studies is quite varied. Only few studies focus specifically on curriculum and mathematical content $[6,13$, 27, 30, 37]. In this regard the research conducted by Miller et al. [36] presents interesting materials elaborated together with a team of teachers aimed at integrating mathematical activities in an IWB interactive environment, emphasising mathematical learning more than technical IWB skills. The paper by Holmes [37] specifically discusses mathematics topics in relation to the affordances provided by the IWB.

Over the studies, no significant differences appear between primary and secondary schools, but it might depend on the issue that generally all the studies (except the one by Swan et al. [11]) are concerned only with one level of education. This issue might require further investigation.

\section{Discussion and Conclusions}

The IWBs potentialities to enhance the quality of interaction (both the social interaction between the teacher and the students, and the content interaction with mathematical concepts), and, consequently, to improve conceptual mathematical understanding and problem solving, are broadly recognized. IWBs have the potential to aid the teaching of difficult, abstract, and complex ideas [7], to improve students' motivation to learn and increase lessons' pace [18], and to reinforce conceptual learning through the use of animation or visual representation [17]. Many of the reviewed studies $[6,13,30,31]$ presented classroom observations in which teachers working with IWBs developed their technological fluency, promoted students' group work activities to deal with real-world problems, and improved innovative processes of exploration with their students.

Despite these potentialities, current evidence from the reviewed studies $[24,28,38]$ points to a certain inertia on the part of many teachers to do anything other than use IWBs as large-scale visual blackboards or presentational tools. Miller et al. [36] reported how too often the IWB is being used for presentational purposes, showing mathematics as an abstract set of rules and theorems.

From this perspective, the history of IWBs may be viewed as a kind of repetition of the repeatedly told story about every new technological innovation (radio, educational TV, computers) in education [43]. At the beginning, expectations of educators reflected the enthusiasm of the initial innovators or "missioners" [27] who were quick to introduce the new technology to their classrooms. The initial expectations exceeded its actual contribution to learning and teaching. There are many exemplary cases of excellent integrations of IWBs into education $[6,13,28,30]$ but in many cases the reviewed studies report about good intentions but mediocre usages.

Salomon and Ben-Zvi [43] pointed out some reasons for the complex relationship between technology and education in general, which also applies to IWBs. First, what Salomon and Ben-Zvi call the "attribution of omnipotence," that is, "the assumption that once you have ICT, new developments are 
likely to follow more or less on their own" (p. 212). "There is nothing omnipotent about the role of ICT and no real change in and of education can take all on its own." (p. 213). It is not the technology per se that can make the difference, but rather the activities that the learning environment in which the technology is embedded affords and brings to life.

Second, reasons for teachers' reluctance to use IWBs in ways other than as presentational tools may be found in what Salomon and Ben-Zvi [43] call the "trivialisation of ICT." Often for many teachers, a transmission view of education dominates, in which good learning means the accumulation of facts and procedures to be reiterated and stored. With respect to this paradigm the role of ICT has potentially subversive characteristics: "by requiring or even just implying a shift of responsibility for learning to the students, a change of the teacher's authoritative role, or the introduction of a more constructivist (i.e., diversity-oriented) approach." ([43] p. 212). The emerging view of how to attempt to overcome these obstacles is that there is need for greater attention to the pedagogy associated with IWB use and to the mathematical tasks concerned, providing teachers with larger training opportunities and stimulating the design of new kinds of learning environments $[13,35]$.

The answer to the main question of this review-whether the use of IWBs in classrooms improves the interactivity in mathematics teaching, and whether this improvement enhances student understanding of basic concepts, encourages idea generation, and better promotes students' achievements-is not definitive. While some studies are critical in this respect, others highlight the IWB potentialities and point to an improvement of pedagogical and mathematical (rather than technological) lessons' design.

Some characteristics that may constitute prerequisites for improving interactivity and characterizing enhanced teaching emerge from the studies presented in this review:

(i) planning for cognitive development: the way in which the IWB was used to underpin lesson structure, and how materials were organised to support learning. As stressed by Glover et al. [6], there is a need for "organised resources" so that the teacher and students could move smoothly between phases of the lessons, so enabling a clear development of thinking between desk-based and board-based activities;

(ii) dialogic teaching: stimulating students to generate and express their ideas, improving students' responses and discussion amongst peers, and promoting forms of team and collaborative learning [17];

(iii) using effective questioning: a move from closed questions to open questions may help to stimulate required reasoning, as pointed out, amongst others, by Miller et al. [36];

(iv) progression: an upward progression of lessons in learning and attainment may offer a clear structure for activities and assessment so that students have a set of targets towards which they are working [6];

(v) immediate feedback: teachers prompting profitable discussion and explanation at some stage in the lesson by getting students to explain, illustrate, and direct from the IWB [36];

(vi) saving previous lessons and recall to strengthen learning from lesson to lesson as a mean of sustaining pupil understanding and achievement, as highlighted by Moss et al. [17].

As pointed out by Stein and Smith [42], to improve mathematics learning high-level mathematical tasks need to engage learners in the processes of mathematical thinking, teaching students that doing mathematics not only consists in applying standard procedures but in reasoning about main mathematical concepts and in solving and managing mathematical problems.

Additional but important features in mathematics learning include the following:

(i) activities that call for an active thinking approach: learning to use concepts and problem solving as a basis for cognitive understanding, exploiting series of activities to explore, develop and reinforce in the lessons, thus facilitating understanding, as discussed for instance in the study by Kennewell et al. [13];

(ii) large-scale use of visual representation of concepts: the ease of visually demonstrating principles on an IWB improves a large variety of visual representations of concepts and examples including graphics, animation, video clips, and associated dynamic software, thus exploiting the multimodal affordances of IWBs, as presented for instance in the studies by Glover et al. [27] and by Jewitt et al. [30];

(iii) using the IWBs' complexity with fluency: to interact with mathematical concepts in real time, such as using dynamic geometrical software, which enabled students to grasp the concept in more depth, as presented in the workshop by Lavicza and Papp-Varga [39].

Four issues for further research emerge from this review study. First, three essential elements appear to be important in the development of an powerful IWB-supported environment for mathematics teaching and learning: (a) the quality of the interaction with the mathematical content, that is, tasks in which students are engaged, (b) the quality of discourse interaction between the teacher and the students and amongst the students, and (c) the affordances that the IWB may provide in terms of supporting interactivity and students' involvement. An accurate orchestration of these elements is required for involving teachers and students in active participation and in developing thinking, together questioning and cobuilding knowledge, supported by the IWB affordances. In this respect, design-based research aiming to capture the complexity of actual teaching and learning processes would be suitable to look into what kind of design could maximise potential interactivity in mathematics lessons and improve educational innovation.

Second, research should investigate what kinds of learning activities and learning goals an IWB environment may promote. Are learning activities and learning goals different 
from those in a traditional environment? And are some learning activities and goals more suitable than others? In this regard research will require a systematic approach (e.g., experimental studies) in order to achieve useful findings that can inform effective practices.

Third, it should be worth to investigate whether there are significant differences in IWB use between primary and secondary schools that are independent from the level of the topics. None of the reviewed studies deals with this issue; nevertheless a comparison of findings at different level of instruction might reveal interesting results.

Fourth, an in-depth look into the question of whether an enhanced IWB environment favours students' cognitive achievements and whether measured learning outcomes are improved when a classroom is systematically taught using IWBs would be very useful. About this issue, the reviewed studies are too few to provide a conclusive answer. In this respect, it would be necessary to take into account the specific learning activities and goals within an IWB learning environment; if they are different from the ones in a traditional environment, these learning goals could lead to the attainment of different learning outcomes. As stated by Littleton [44] with regard to IWB-embedding in learning environments,

"Sociocultural processes such as those of continual
technological change and the changing nature
of childhood intersect, and force us to consider
whether we look to technologies to enable learners
and teachers to do things better or do things
differently." (p. 290)

While revealing interesting insights, this review does have its limitations. First, for the reasons explained above, it refers only to the literature about the use of IWBs in mathematics teaching in primary and secondary schools and thus does not include relevant studies not implying mathematics. Second, it pores mainly over literature from the UK. Despite IWB use's spread to other countries, most studies come from that country, where IWBs are adopted in a large number of schools. Few studies are available from other countries, and none of them are grounded on classroom observation, with the exception of the studies by Zevenberger and Lemann $[12,34]$ and by Serow and Callingham [32] in Australia. Third, not all of the studies taken in account are peerreviewed. Some are final reports of the Schools Whiteboard Expansion pilot projects in England, which evaluated the IWB embedding in primary and secondary schools, and some are contributions and suggestions on adapting curricula and enhancing IWB practice, or on improving teachers' performances. They were all included in this review to provide a better frame of the relationships between IWBs and education.

Despite these limitations, hopefully this review will help a better understanding of the issues underlying the IWBs integration in mathematics teaching environments and will address further research to enhance and improve their use in an effective and incisive design.

\section{Conflict of Interests}

The authors declare that there is no conflict of interests regarding the publication of this paper.

\section{References}

[1] H. J. Smith, S. Higgins, K. Wall, and J. Miller, "Interactive Whiteboards: boon or bandwagon? A critical review of the literature," Journal of Computer Assisted Learning, vol. 21, no. 2, pp. 91-101, 2005.

[2] G. Beauchamp and J. Parkinson, "Beyond the "wow" factor: developing interactivity with the interactive whiteboard," School Science Review, vol. 86, no. 316, pp. 97-104, 2005.

[3] S. Kennewell, "Reflections on the interactive whiteboard phenomenon: a synthesis of research from the UK," 2006, http:// www.aare.edu.au/06pap/ken06138.pdf.

[4] N. Mercer, S. Hennessy, and P. Warwick, "Using interactive whiteboards to orchestrate classroom dialogue," Technology, Pedagogy and Education, vol. 19, no. 2, pp. 195-209, 2010.

[5] BECTA (British Educational Communications and Technology Agency), "Getting the most from your interactive whiteboard: a guide for secondary schools. Coventry, UK: BECTA," 2004, http://www.dit.ie/lttc/media/ditlttc/documents/gettingthemost .pdf.

[6] D. Glover, D. Miller, D. Averis, and V. Door, "The evolution of an effective pedagogy for teachers using the interactive whiteboard in mathematics and modern languages: an empirical analysis from the secondary sector," Learning, Media and Technology, vol. 32, no. 1, pp. 5-20, 2007.

[7] B. Somekh, M. Haldane, and K. Jones, "Evaluation of the primary schools whiteboard expansion project," Tech. Rep., Department for Education and Skills, London, UK, 2007, http: //webarchive.nationalarchives.gov.uk/20130401151715/https:// www.education.gov.uk/publications/eOrderingDownload/ SWEEP-Report.pdf.

[8] B. Torff and R. Tirotta, "Interactive whiteboards produce small gains in elementary students' self-reported motivation in mathematics," Computers \& Education, vol. 54, no. 2, pp. 379383, 2010.

[9] C. Bruce, R. McPherson, F. Sabeti, and T. Flynn, "Revealing significant learning moments with interactive whiteboards in mathematics," Journal of Educational Computing Research, vol. 45, no. 4, pp. 433-454, 2011.

[10] D. Miller and D. Glover, "Presentation or mediation: is there a need for "interactive whiteboard technology-proficient" teachers in secondary mathematics?" Technology, Pedagogy and Education, vol. 19, no. 2, pp. 253-259, 2010.

[11] K. Swan, J. Schenker, A. Kratcoski, and H. van't Hooft, "The effects of the use of interactive whiteboards on student achievement," in Interactive Whiteboards for Education: Theory, Research and Practice (Premier Reference Source), M. Thomas and E. C. Schmid, Eds., pp. 131-143, Information Science Reference, Hershey, NY, USA, 2010.

[12] R. Zevenbergen and S. Lerman, "Learning environments using interactive whiteboards: new learning spaces or reproduction of old technologies?" Mathematics Education Research Journal, vol. 20, no. 1, pp. 108-126, 2008.

[13] S. Kennewell, H. Tanner, S. Jones, and G. Beauchamp, "Analysing the use of interactive technology to implement interactive teaching," Journal of Computer Assisted Learning, vol. 24, no. 1, pp. 61-73, 2008. 
[14] Ofsted (Office For Standards in Education, UK), "Mathematics 2004-07: understanding the score. London: HMSO," 2008, http://www.ofsted.gov.uk/resources/mathematics-understanding-score.

[15] A. Heinze, J. R. Star, and L. Verschaffel, "Flexible and adaptive use of strategies and representations in mathematics education," Mathematics Education, vol. 41, no. 5, pp. 535-540, 2009.

[16] D. Miller and D. Glover, "Into the unknown: the professional development induction experience of secondary mathematics teachers using interactive whiteboard technology," Learning, Media and Technology, vol. 32, no. 3, pp. 319-331, 2007.

[17] G. Moss, C. Jewitt, R. Levaãiç, V. Armstrong, A. Cardini, and F. Castle, "The interactive whiteboards, pedagogy and pupil performance evaluation: an evaluation of the Schools Whiteboard Expansion (SWE) Project: London Challenge," Tech. Rep., School of Educational Foundations and Policy Studies, Institute of Education, University of London, London, UK, 2007, http://www.pgce.soton.ac.uk/ict/NewPGCE/pdfs\% 20IWBs/The\%20interactive\%20whiteboard,\%20pedagogy\%20 and\%20pupil\%20performance\%20evaluation.pdf.

[18] S. Higgins, C. Falzon, I. Hall et al., "Embedding ICT in the literacy and numeracy strategies," Final Report, Newcastle University, Newcastle, UK, 2005, http://dro.dur.ac.uk/1899/1/1899.pdf? DDD29+ded4ss.

[19] A. H. Schoenfeld, "Learning to think mathematically: problem solving, metacognition, and sense-making in mathematics," in Handbook for Research on Mathematics Teaching and Learning, D. Grouws, Ed., pp. 334-370, MacMillan, New York, NY, USA, 1992.

[20] J. L. Galvan, Writing Literature Reviews: A Guide for Students of the Social and Behavioural Sciences, Pyrczak Publishing, Los Angeles, Calif, USA, 2006.

[21] S. Merrett and J. Edwards, "Enhancing mathematical thinking with an interactive whiteboard," MicroMath, vol. 21, no. 3, pp. 9-12, 2005.

[22] M. Thomas and C. E. Schmid, Eds., Interactive Whiteboards for Education: Theory, Research and Practice (Premier Reference Source), Information Science Reference, Hershey, NY, USA, 2010.

[23] S. Higgins, G. Beauchamp, and D. Miller, "Reviewing the literature on interactive whiteboards," Learning, Media and Technology, vol. 32, no. 3, pp. 213-225, 2007.

[24] F. Smith, F. Hardman, and S. Higgins, "The impact of interactive whiteboards on teacher-pupil interaction in the National Literacy and Numeracy Strategies," British Educational Research Journal, vol. 32, no. 3, pp. 443-457, 2006.

[25] B. Tataroglu and A. Erduran, "Examining students' attitudes and views towards usage an interactive whiteboard in mathematics lessons," Procedia-Social and Behavioral Sciences, vol. 2, no. 2, pp. 2533-2538, 2010.

[26] S. Jones and H. Tanner, “Teachers' interpretations of effective whole class interactive teaching in secondary mathematics classrooms," Educational Studies, vol. 28, no. 3, pp. 265-274, 2002.

[27] D. Glover, D. Miller, and D. Averis, “The impact of interactive whiteboards on classroom practice: examples drawn from the teaching of mathematics in secondary schools in England," in Proceedings of the International Conference "The Decidable and the Undecidable in Mathematics Education", Brno, Czech Republic, 2003, http://math.unipa.it/ grim/21_project/21_brno03_Miller-Averis.pdf.
[28] D. Miller, D. Averis, V. Door, and D. Glover, "How can the use of an interactive whiteboard enhance the nature of teaching and learning in secondary mathematics and modern foreign languages?” Tech. Rep., BECTA, 2005, https://content.ncetm .org.uk/itt/sec/KeelePGCEMaths2006/InteractiveWhiteboard \&DataProj/Research/BectaReportMiller\&co.pdf.

[29] D. Miller, D. Glover, and D. Averis, "Presentation and pedagogy: the effective use of interactive whiteboards in mathematics lessons," in Proceedings of the 6th British Congress of Mathematics Education, D. Hewitt and A. Noyes, Eds., pp. 105-112, British Society for Research into Learning Mathematics, London, UK, 2005, http://www.bsrlm.org.uk/IPs/ip25-1/BSRLM-IP-251-14.pdf.

[30] C. Jewitt, G. Moss, and A. Cardini, "Pace, interactivity and multimodality in teachers' design of texts for interactive whiteboards in the secondary school classroom," Learning, Media and Technology, vol. 32, no. 3, pp. 303-317, 2007.

[31] G. Beauchamp, S. Kennewell, H. Tanner, and S. Jones, "Interactive whiteboards and all that jazz: the contribution of musical metaphors to the analysis of classroom activity with interactive technologies," Technology, Pedagogy and Education, vol. 19, no. 2, pp. 143-157, 2010.

[32] P. Serow and R. Callingham, "Levels of use of interactive whiteboard technology in the primary mathematics classroom," Technology, Pedagogy and Education, vol. 20, no. 2, pp. 161-173, 2011.

[33] R. Wood and J. Ashfield, "The use of the interactive whiteboard for creative teaching and learning in literacy and mathematics: a case study," British Journal of Educational Technology, vol. 39, no. 1, pp. 84-96, 2008.

[34] R. Zevenbergen and S. Lerman, "Pedagogy and interactive whiteboards: using an activity theory approach to understand tensions in practice," in Mathematics: Essential Research, Essential Practice, K. Beswick and J. Watson, Eds., Proceedings of the 30th Annual Conference of the Mathematics Education Research Group of Australasia, pp. 853-864, MERGA, Adelaide, Australia, 2007, http://www98.griffith.edu.au/dspace/bitstream/handle/10072/18685/49294_l.pdf?sequence=1.

[35] D. Glover and D. Miller, "Optimising the use of interactive whiteboards: an application of developmental work research (DWR) in the United Kingdom," Professional Development in Education, vol. 35, no. 3, pp. 469-483, 2009.

[36] D. Miller, D. Glover, and D. Averis, "Enabling enhanced mathematics teaching with interactive whiteboards," Final Report, National Centre for Excellence in the Teaching of Mathematics, Keele University, Keele, UK, 2008, http://www .keele.ac.uk/media/keeleuniversity/fachumsocsci/sclpppp/education/interactivewhiteboard/ncetmreport-1.pdf.

[37] K. Holmes, "Planning to teach with digital tools: introducing the interactive whiteboard to pre-service secondary mathematics teachers," Australasian Journal of Educational Technology, vol. 25, no. 3, pp. 351-365, 2009.

[38] D. Miller and D. Glover, "Enhanced interactivity in secondary mathematics," in Interactive Whiteboards for Education: Theory, Research and Practice, M. Thomas and E. C. Schmid, Eds., pp. 118-130, Information Science Reference, Hershey, NY, USA, 2010.

[39] Z. Lavicza and Z. Papp-Varga, "Integrating GeoGebra into IWB-equipped teaching environments: preliminary results," Technology, Pedagogy and Education, vol. 19, no. 2, pp. 245-252, 2010. 
[40] R. Straesser, "Cabri-géomètre: does Dynamic Geometry Software (DGS) change geometry and its teaching and learning?" International Journal of Computers For Mathematical Learning, vol. 6, no. 3, pp. 319-333, 2001.

[41] D. Essig, A case study of interactive whiteboard professional development for elementary mathematics teachers [Doctoral dissertation], UMI Dissertation Publishing no. 3450045, ProQuest, Ann Arbor, Mich, USA, 2011.

[42] M. K. Stein and M. Smith, "Reflections on practice: selecting and creating mathematical tasks: from research to practice," Mathematics Teaching in the Middle School, vol. 3, no. 5, pp. 344350, 1998.

[43] G. Salomon and D. Ben-Zvi, "The difficult marriage between education and technology: is the marriage doomed?" in Instructional Psychology: Past, Present, and Future Trends, L. Verschaffel, F. Dochy, M. Boekaerts, and S. Vosniadou, Eds., pp. 209-222, Elsevier, Oxford, UK, 2006.

[44] K. Littleton, "Research into teaching with whole-class interactive technologies: emergent themes," Technology, Pedagogy and Education, vol. 19, no. 2, pp. 285-292, 2010. 

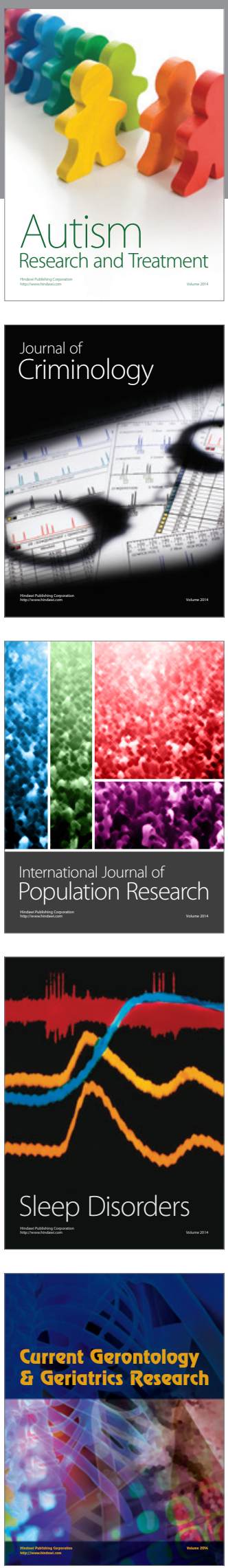
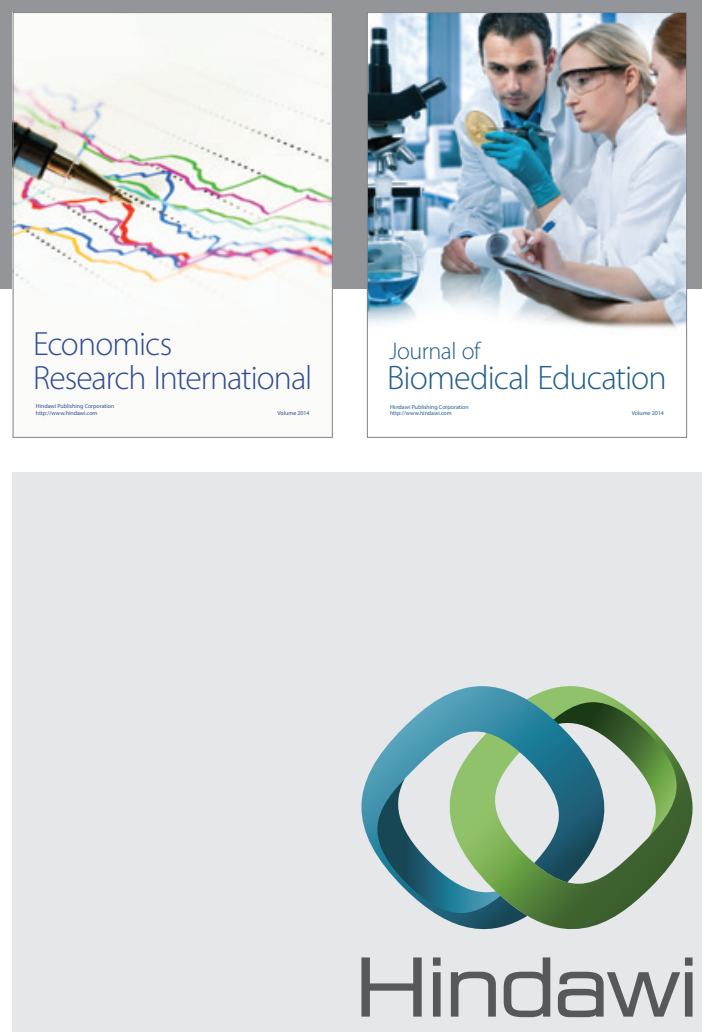

Submit your manuscripts at

http://www.hindawi.com
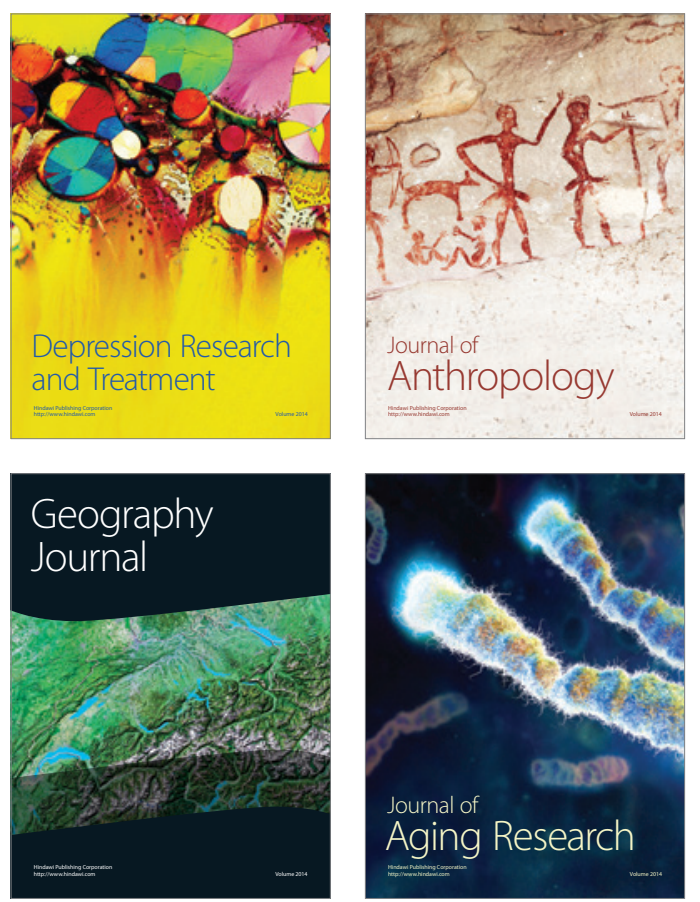
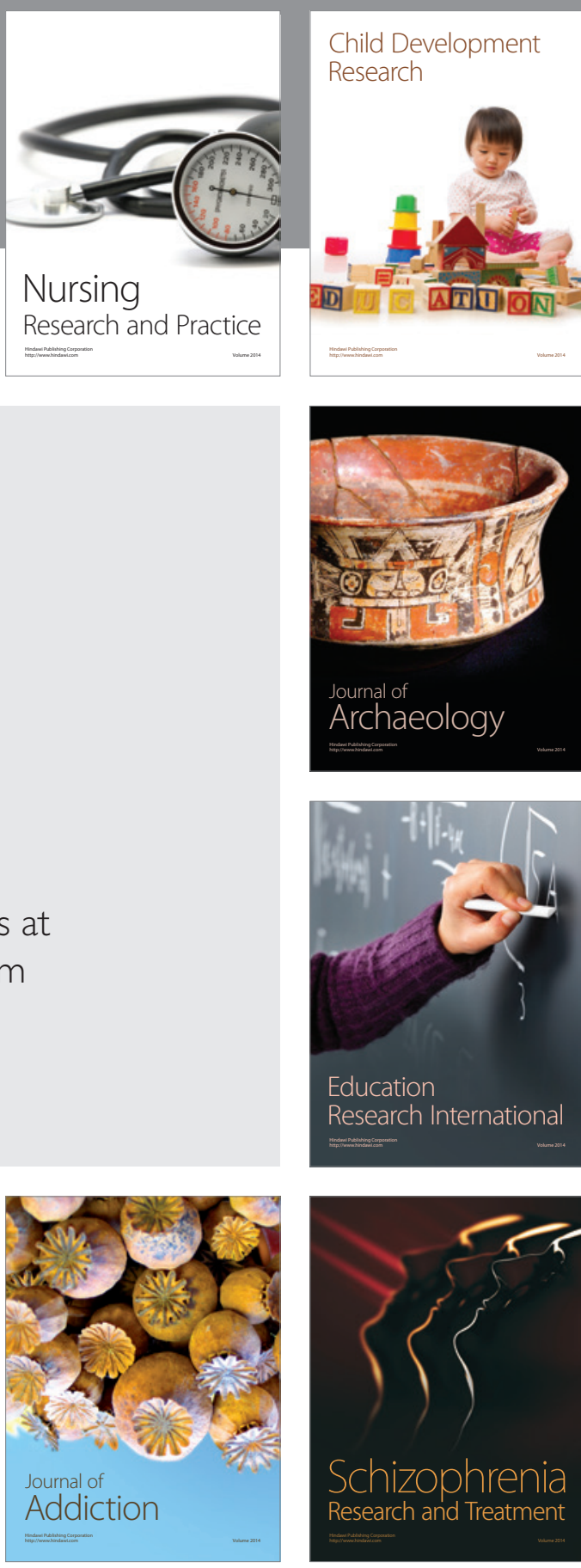

(D)
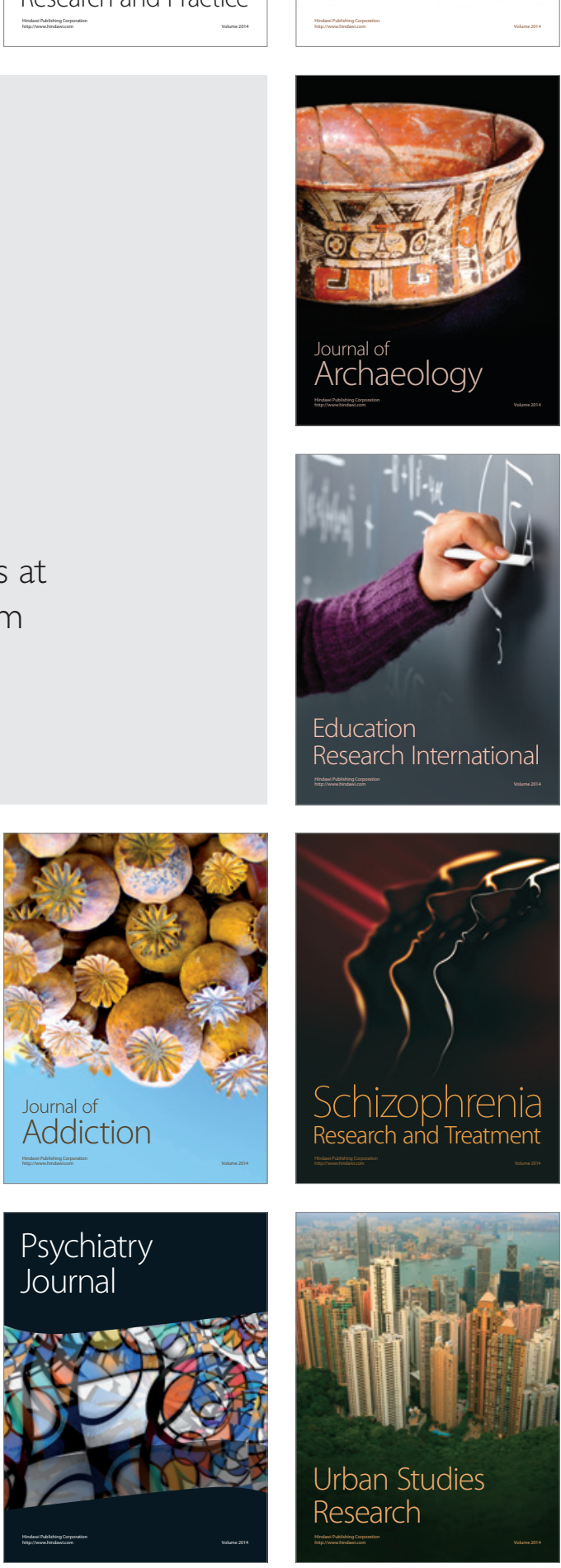